Volume 7, Issue 1, 1-6 Pages

Research Article | Open Access

ISSN (Online)- 2378-7031

DOI :



\title{
Social Transformations and Prospects for the Development of the Education System
}

\author{
Viktor Zinchenko ${ }^{1 *}$, Lesya Chervona ${ }^{2}$, Nataliia Fialko ${ }^{3}$, Mykola Iehupov ${ }^{4}$
}

${ }^{* 1}$ Doctor of Sciences (Philosophical), Professor, Head of Higher Education Internationalization Department of

Internationalization \& Principal researcher in Department of University Research Activities of the Institute of Higher

Education of the National Academy of Educational Sciences. Kyiv, Ukraine.

${ }^{2}$ Institute of Higher Education of the National Academy of Educational Sciences, Kyiv, Ukraine.

${ }^{3}$ National University of Physical Education and Sports, Kyiv, Ukraine.

${ }^{4}$ National University of Physical Education and Sports, Kyiv, Ukraine.

\begin{abstract}
The achieving of the purpose of social development of education and upbringing, which are often reduced by neobehaviorism in fact to the manipulation of people, requires somewhat different and more appropriate methods. Such methods should include various forms of training, behavior modification based on the factors of reinforcement techniques (variety of motivation, encouragement, rewards, etc.). Individuals must be clearly aware of the purpose of their activity, and at the same time, the effectiveness of social reinforcement depends on the degree of trust and respect of the individual to the institutions of society and the specific people to whom society and the state are entrusted to carry out the administrative-managerial process.
\end{abstract}

KEYWORDS: social transformation, education system, neo-behaviorism, social reinforcement, universities, trust, administrative-managerial process.

\section{INTRODUCTION}

The scientific-technocratic direction presents autocratic positions on education and public administration. It is based mainly on the concept of "behavioral technology" of the founder of modern behaviorism Burrhus Frederic Skinner and in general on behavioral psychology. The ideas of the philosophy of education of neo-behaviorism in their direct application to certain applied tasks and problems are shared by a large group of philosophers, educators, psychologists, represented primarily by Edward K. Morris, Nathaniel G. Smith and others. They see their goal in constructing a "controlled individual" that is quite convenient for a "total society" by modifying behavior. That is why behaviorism - and subsequently neo-behaviorism - abandoned the accepted concept of free choice of actions by the individual, as if not appropriate to human nature, proposing to replace it with the concept of "formed automatic skills". The latter, in their opinion, are not only effective in terms of controlling the behavior of the individual, but also increase the chances of survival of modern civilization. Based on this, another concept is introduced into the theory - "automatically correct behavior". They were trying to invest it in the basis of various models of social actions in the interests of public manipulators and controllers [8].

Proponents of this trend reject the idea of self-expression as one of the important goals of education, seeing this as one of the main causes of social and moral crisis. They proceed from the premise that man is a so-called "learning being", and in the process of learning it is developed all the norms of his behavior. The effectiveness of training is achieved by introducing into the educational system the achievements of science and technology, politics and economics, experimental methods. This creates the impression of a strictly "scientific", rationalist approach to education / upbringing and provides a significant impact of these concepts on the political, economic and educational establishment, as well as among certain groups of society, including the scientific intelligentsia.

In the American model of education, it is informally believed (based on the pedagogical ideas of "technology of education and upbringing" of behavioral psychology, neo-behavioral philosophy of education and post-behavioral ideology) that modern developed society needs mostly quality performers. Creative thinking people, self-sufficient persons, of course, are also needed but it is rare need. Therefore, the entire 
education system should be set up to select, cultivate and modify the actions of quality performers, and teach young people to think analytically is absolutely not necessary: in modern society it will only harm their future professional activities, whatever it may be [2]. At the school and university level, it is important to simply select and train the most obedient, hard-working, that is, above all, quality performers. As for creative people, they should not be particularly worried about: the one who is really talented, one way or another will still "break through" [3].

\section{MATERIALS AND METHODS}

According to the prevailing principles of pedagogy and philosophy of neo-behavioral education, all life, educational aspirations and requests, both personal and professional, must be clearly algorithmically and purposefully modified according to the goals, values and direction of the state and society [4]. It is believed that abilities should be tested in different schools and by different people. Exceptions are rare and mostly for the regions where the labor market is relatively small. This approach is also based on the Protestant idea of corporate social responsibility; and the education system as one of the forms of manifestation of this responsibility - was formed on the basis of these values (neo-behavioral philosophy of education and Protestant social and business ethics).

Also methodological and philosophical-educational basis for this system of education (as for the closely related system of public education) is the philosophy of education of pragmatism and neo-pragmatism, which is based on the development of John Dewey's ideas, according to which the intellectual and ethical qualities of the person in its unique nature and their manifestation is associated primarily with individual human experience [5]. Representatives of pragmatism and neo-pragmatism in the philosophy of education see the tasks of education primarily in the quantitative growth of the individual's abilities, qualities (primarily intellectual) and his individual experience as the main condition for self-realization. Individual experience, according to Dewey and his followers, also determines the nature and character of socio-moral norms and principles - the "tools" that the individual at its discretion chooses in each situation to succeed. Related to this provision is the conclusion of supporters of the politico-economic neoconservative trend for that the growth of individual experience, which leads to success, is the main criterion of socially useful behavior [6]. Moreover, the question of the nature of the values from which persons proceed in their activities and behavior, these economists consider meaningless.

It should be noted at the outset that the American model of higher education also reflects the specifics of worldviews, social orientations and social demands - Americans deal with education in pragmatic way inherent to them. For them, training programs and courses are a product that differs in quality and price. For the United States the principle of specialization of education, not the unifying of it is inherent.

The ideological and worldview basis that is provided into the administrative and managerial educational-scientific system and organizational structure of the university is mainly "scientific-technocratic" and "conservative" paradigm (mainly in the form of concepts of "neo-behaviorism", "pragmatism and neo-pragmatism"). It is common (according to the model, but not according to directions and not according to ideological principles) with the "Anglo-Saxon" educational and scientific system [7].

This direction includes pragmatist and utilitarian conceptions of education, close to the target settings and criteria for assessing of the human behavior, associated with the philosophy of pragmatism and neo-pragmatism as the most typical for this area. This ideological and applied system is represented primarily by the philosophy of education and ethics of John Dewey, as well as modern modifications of his concept of education (philosophy of neo-pragmatism), whose theorists are Theodore Brameld, Carl Rogers, Earl Kelley and others. Neo-pragmatist modifications are largely based on behaviorist and Freudian psychology. This allowed the leader of the so-called Abraham Maslow's humanistic psychology of management, as well as his followers to join the neo-pragmatist concept.

\section{RESULTS AND DISCUSSION}

The methodological basis of the conservative direction in education is Dewey's thesis, according to which the intellectual and ethical qualities of the person are inherent in its unique nature and their manifestation is associated primarily with individual human experience. Hence, the task of education and upbringing for the representatives of pragmatism lays not in the formation of certain principles, value orientation of the individual, but only in the quantitative growth of data given to him by the nature of abilities, qualities, knowledge and individual experience as the main condition of self-realization. Unlike Dewey, neo-pragmatists believe that beyond this, the process of education also implies the development of human creative abilities, which requires skillful organization of human activities.

Education in this approach is subject to a purely utilitarian goal, above all - to increase productivity, as well as the acquisition of skills to learn moral norms, attitudes of social environment, political and state ideology and strict, unquestioning obedience to these attitudes. The main means of implementing such a program is strict control by the social environment through the mechanism of "reinforcement", ie a system of incentives or penalties for the slightest deviation from the program. This mechanism (especially its repressive side) is designed to ensure the reliability of people, especially young people, to form in them a need to obey existing norms in society, requirements that often (especially in transitional 
or transitional societies) reflect the interests of the ruling elite.

Based on the system of "reinforcement" technocratic concepts pay special attention the appearance of voluntary submission of the individual to these requirements and thus achieve "harmony" between the consciousness of the individual and society. However, this very "harmony" they often interpret as serving the abstract general ideals o the state, nation, society (and the "System" in general) to the detriment of personal interests, and the sense of responsibility is interpreted as a manifestation of loyalty to society, principles state and political institutions and attributes of power.

According to neo-behaviorists, with the help of such control it is possible to solve important humanistic problems. Following the thesis that modern society should be based on "rational thinking", supporters of the neo-behavioral philosophy of education and management focus on the education and formation of a person whose ideal would meet the requirements of industrial society. By influencing different layers of the human psyche, they seek to educate not a holistic personality, but a scientifically oriented, technically educated person who is destined to remain infantile in matters of politics, general culture and morality. These methods are traditionally actively introduced into the system of social management and educational institutions in the United States.

In American everyday, all universities are usually called colleges, even if they are not colleges but universities. US universities can be divided into three types, which usually differ significantly from each other, mainly in the number of students and goals. There are several thousand different universities in the United States, which can be classified in many ways. Thus, according to the form of funding they are divided into two groups: the largest group consists of private institutions (students pay for tuition, self-financing of universities, private donations, sponsorship, a smaller share of budget funds) and public (much of the funds come from federal and local budgets ). In general, the state still has a dominant role, funding a significant share of research programs in universities, maintaining two- and four-year colleges with almost $80 \%$ of the total contingent of students [1].

One of the main characteristics and differences of US universities is the presence or absence of research programs and graduate programs that distinguish college from university. The college is a higher education institution that deals mainly with the education of students, and scientific work, if any of it takes place here, remains in the background. The vast majority of four-year colleges are small (less than 2,000 students) and private, although state colleges for talented local students have recently begun to appear. Many small colleges are religious, sometimes called "bible colleges." Humanities colleges are often referred to as "liberal arts colleges." The best liberal arts colleges, such as Amherst, Williams, and Swarthmore, are comparable in prestige to universities, but because they are much smaller, they are less known, although the quality of education there is often better.

Most American universities have a well-developed research structure at the doctoral level, the rest are multidisciplinary universities with a large number of bachelor's and master's degree programs. Universities are divided into two types: federal-level universities and state-funded state universities. State universities are often very large and tend to be somewhat inferior to private ones. Their main goal is to teach local students from the state, and therefore for students from other states, both the competition and the tuition fee are usually higher.

Therefore, according to the structure, level and content of education, American specialists divide their universities into the following groups:

- institutions of post-secondary education of various types and semi-vocational schools with programs lasting from 1 to 3 years and the award of certificates of low levels. Short education ends with a certificate of certain professional skills, longer - the award of an associate degree (Associate Degree) with the right to perform the work of technicians and admission to the third year of colleges with bachelor's programs;

- local and junior colleges with two-year programs, the finishing of which opens the door to the third year of "bachelor's" colleges and to obtain an associate degree or professional license (Occupational License);

- Colleges of Liberal Arts, which is an essential feature of the US higher education system, with the teaching of almost exclusively general disciplines such as history, chemistry, economics, etc. and the award of a bachelor's degree with a dominant academic and minimum professional background. However, there is a noticeable tendency to include professional courses in the final years of the four-year program, which expands the opportunities for graduates. But for certain specialties, such as medicine and law, to obtain a professional qualification, the student must also undergo a postgraduate professional training program to achieve a master's degree in university schools;

- comprehensive colleges with a bachelor's and master's degree (programs include pre-professional and in-depth professional development). Most of these institutions train teachers, businessmen, specialists whose activities require a master's degree;

- independent vocational schools with bachelor's (often master's) level degrees in technology, arts, etc. With the content of the programs close to the institutions of the first group, these schools use much more qualified staff with university training; 
- universities with the right to train doctors and all cycles of study, which form the most prestigious group of higher education institutions. These include undergraduate colleges, master's schools and above. This group is often differentiated into narrower ones, based on the level of research (the number and thematic diversity of doctoral dissertations defended each year), the amount of research funding, the presence or absence of a medical school with a research clinic, the range of faculties, and the ratio of teachers and students.

Among the usual ones we also have a separate group of higher education institutions that widely use state-of-the-art means of information transfer and organization of distance learning. Among the first was the well-known company IBM, which used two-way video communication via satellite to train its staff simultaneously on both shores of the Atlantic Ocean. Nowadays, teleconferences of scientists have become commonplace. Instant teaching by teachers and groups of students in the United States is also increasingly used [9].

In general, the structure of American universities is very diverse, but the main link, which performs most of their tasks, is a small branch or department, the head of which can be appointed and elected. He and his colleagues solve all issues of teaching a certain discipline and research work in the department. Higher levels (departments, educational colleges and the whole institution) only approve the collective decisions of the department. In the largest US universities, applicants usually have to enroll in a particular department, but at the same time, in most universities, he enters this institution of higher education in general, making his final choice of department and specialty after successful selection tests and enrollment. Even where one have to enter the department, there are ways to move from department to department and the opportunity to have the status of "not made one's choice", although the path to some faculties becomes almost or completely closed. In other universities, the student have to decide what to specialize at the end of the first and sometimes second year. Sometimes, in addition to the major specialization (major), one can add some minor specializations, and sometimes one can choose two or even three majors.

In US universities, there are relatively many different qualifications, diplomas and certificates awarded after completing programs of different levels [10].

There are three levels of higher education.

The first is the level of bachelor's degree training, which usually lasts four years (except for medicine, law and some other specialties). Diplomas (Bachelor's Degree) of this level in content - mostly academic qualifications and are represented by diplomas of Bachelor of Arts or Bachelor of Science.

The second level program after specialization in a certain field in 1-2 years ends with the award of a master's degree (Master Degree). The requirements for obtaining it are various: writing abstracts (scientific work), passing an exam in a foreign language, certification of the ability to use computers and databases, final exams. The flexible degree system of the American higher school allows to interrupt the training at any level, to change a profile of training, to continue education. Only bachelors who have a grade not lower than "B", a positive characteristic, a written recommendation from one or two teachers are selected for master's and doctoral studies. They must successfully pass the exams, which are held twice a year. The term of study in a master program depends on features of a specialty: from one and a half years in the field of arts to two-three years in medicine and psychology. At the end of the study it is necessary to write an abstract review, submit a thesis or pass an exam.

With higher educational qualifications (masters and PHD), too, not everything is clear. In some universities in some specialties may not be so-called terminal MA, which is reported in advance on the website of the university. This means that you will not be able to get a master's degree and leave without then trying to enter graduate school, because these are interrelated programs. Often people in MA / PhD stay at the same university. This is right, because the magistrate is considered the first degree to graduate school and, accordingly, refers to the graduate (graduation with the right of academic growth), and not to undergraduate studies (ordinary study of a final year student).

The third level is doctoral studies (postgraduate studies) and preparation of a doctoral thesis, which requires scientific studies for 3-5 years after obtaining a master's degree. The main criterion for selecting candidates for doctoral studies is the ability to do research. During 2-3 years of study, the doctoral student must master a significant amount of theoretical material, receiving up to 72 credits from 20 exams, pass qualifying exams and defend a dissertation. Current requirements depend on the field of study: scientific work and defense of a dissertation written on its material, general or professional exams, etc. The latter are formed mainly during the first two years of doctoral studies. Usually, after completing the third level of higher education, the title of Doctor of Philosophy (PhD) is awarded, which is the highest academic title in the United States.

Leading US universities have another type of degree training - postdoctoral ("postdoc"), designed to test their scientific ideas and experimentally confirm them; without "postdoc" it is possible to take positions - instructor, lecturer or professor. Postdoc as a postdoctoral teaching and research activity involves professional implementation at a university other than the one where the PhD was obtained. After that, it is possible to obtain a guaranteed permanent professional status - full professor with a de facto life contract.

In the United States, the usual system for Europe to "stay 
at the department after the defense" does not exist. PdD awarders are looking for a job outside their university - these are unspoken rules. One can "stays" in the "native" university only if he had worked in another university for several years before. It is believed that abilities should be tested in different schools and by different people. Exceptions are rare and mostly for that regions where the labor market is relatively small. In any very narrow field, in which a handful of specialists are involved, there is no need to talk about rapid personnel transfers, and here they can really "stay" - but this is not the most typical situation. Bachelor's and master's degrees are also usually obtained in different universities.

Therefore, this system deals education with its some ideological pragmatism, according to which, curricula and courses are a product that differs in quality and price. American colleagues explain that a certain low level of general culture of graduates in the education system in their country is a conscious desire to achieve economic goals. The fact is that a creatively educated person becomes the worst buyer-consumer [11]. The economy of the consumer society suffers from this and, above all, the income of the "masters of life" - so they seek to avoid cultural and unskilled education (which, in addition, hinder economic, political and ideological manipulation of thinking and behavior).

The less people read, critically analyze, theorize, the less they know and the more indoctrinated they become, accepting this nationally encouraged ignorance, they drop into the bottomless spiritual and intellectual-cultural pit. This indicates a certain inability of American education to "produce brains" equipped with what is essential for the survival of democracy: the ability to analyze and ask questions, because everything you encounter in the annals of knowledge is the enemy of this system of commerce and the US education system under its control. Therefore, the only form of education that can be allowed is to enshrine the status quo in culture, as is the case in expensive schools / universities, or to make people protect and enforce the status quo, as in the average US education system. It is noteworthy that in this "average educational system", thirdgrade educational institutions that serve mainly the working class, first-generation college graduates who go to work in the lower echelons of civil service, education or middle management, favorite areas of academic interest - these are communications, criminal justice and social work essentially focused on how to mislead, retain and control the masses.

\section{CONCLUSIONS}

Putting in advance the achievement of success as the main goal of human life, supporters of the pragmatic concept of philosophy of education limit success only to the individual framework of human life and free it from the need to set a high goal, to seek the social ideal. According to John Dewey, in each specific situation a person seeks to realize his individual goal, and therefore he must, based on their abilities, be satisfied with the achieved position [12]. Thus, Dewey inclined to maintain the existing inequality of goals and means in society, that contradicts the proclaimed by him need for egalitarian (based on equality) education.

In contrast, neo-pragmatists believe that beyond this, the educational process also implies the development of human creative abilities, which requires skillful organization of human activities (quality management of education) [13]. Therefore, the origins of the current educational achievements and problems of US education can be traced back to the early twentieth century, when such educational theorists as Ellwood Patterson Cubberley and others, tried to bring school curricula to the needs of the US economy, developing the so-called "scientific approach" (by analogy with the "scientific / rational approach" in the management of that time) to development and planning of education.

Realization of the purpose of social development of education and upbringing, which are often reduced by neo-behaviorism in fact to the manipulation of people, requires appropriate methods, which include various forms of training, behavior modification based on factors of reinforcement techniques (various forms of motivation, encouragement, rewards, etc.). The purpose of the activity of individuals must be clearly aware of, and at the same time, the effectiveness of social reinforcement depends on the degree of trust and respect of the individual to the institutions of society and the specific people to whom society and the state are entrusted to carry out the administrative- managerial process.

Proponents of the neo-behavioral system consider as subjects of the socio-political system only individuals who are subject to manipulation, without taking into account their inner world, their individual characteristics. They consider it necessary to explain the inner world of man in terms of social reinforcement, replacing, wherever possible, the "needs of the human soul" with various kinds of sanctions. Therefore, in any disorder between the individual and soc. environment see only behavioral, not social. a problem that they believe can be solved by forming a new procedure reinforcement techniques. Authorities take on the role of a faceless technocrat who seems to simply rely on science to discover the best that lies in everyone. Citizens need only be aware of the link between bureaucratic guidelines and incentives from society.

The ideas of "technocratic concepts" of education have found their practical embodiment in various forms of "behavior modification" - this is one of the main concepts of neobehaviorism. Behavior modifiers believe that the "system" (in particular - education, upbringing, state, society, etc.) should control as wide a range of people as possible to ensure its effectiveness in terms of their transformation into de facto "social machines", accepting law and authority as constant and necessary existing things. The essence of control is to 
develop in a person a certain psychological and behavioral attitude, readiness to adapt to any requirements of the sociopolitical system under the threat of punishment, to suppress their desire for self-expression, to form conformal behavior. Under these conditions, the objective moral norms and rules developed by mankind are completely alienated from the individual.

\section{REFERENCES}

1. Shelley P.B. A Philosophical View of Reform, (Lexington KY: Ulan Press, 2012) 114 p.

2. Pattern V. Social control and human engineering: A framework for humanistic decision (Bangor : University Press, 2011) 227.

3. Kozol J. The Shame of the Nation: The Restoration of Apartheid Schooling in America (New York: Broadway Books, 2014) 432.

4. Feinberg W. Behavioral theory and education (Boston: Prentice-Hall, 1994) 467.

5. Dewey J. Reconstruction in Philosophy (Boston: Beacon Press, 1957) 156.

6. Kwiek M. The University and the State. A Study into Global Transformations (Frankfurt am Main: Peter Lang, 2006) $424 \mathrm{p}$.
7. Zinchenko V. Global institutional transformation strategies of self-management systems. Zeszyty Naukowe Wyższej Szkoły Humanitas Zarządzanie, 2015, 4, 169176.

8. Buchanan P.J. The Death of the West: How Dying Populations and Immigrant Invasions Imperil Our Country and Civilization (New York:Thomas Dunne Books, 2002) 320.

9. Zinchenko V. Institutional transformations systems of society and perspectives of critical theory in the social philosophy of education. Pedagogika Filozoficzna, 2015, 1, 59-68.

10. Byram M. and Dervin F. (eds.) Students, staff and academic mobility in higher education (Newcastle-uponTyne : Cambridge Scholars Publishing, 2018) 320.

11. Sintschenko V. Welches Wirtschaft Wissen? Welche Soziale Gesellschaft? WISSENSGESELLSCHAFT. Textbeitrag «Gut zu Wissen», 2016, 11, 71.

12. Dewey J. Reconstruction in Philosophy (Boston: Beacon Press, 1957) 31.

13. Rogers C.R. «Toward Becoming a Fully Functioning Person». In: Perceiving, Behaving, Becoming: A New Focus for Education.Yearbook. Ed. A. W. Combs (edited by A. W. Combs) (Washington, DC: Association for Supervision and Curriculum Development, 1999) 12.

Citation: Viktor Zinchenko, Lesya Chervona, Nataliia Fialko, Mykola Iehupov, "Social Transformations and Prospects for the Development of the Education System", American Research Journal of Humanities and Social sciences, Vol 7, no. 1, 2021, pp. 1-6.

Copyright (C) 2021Viktor Zinchenko, Lesya Chervona, Nataliia Fialko, Mykola Iehupov, Sulaiman Kayode, This is an open access article distributed under the Creative Commons Attribution License, which permits unrestricted use, distribution, and reproduction in any medium, provided the original work is properly cited. 